\title{
The antimicrobial landscape as outlined by Danish dairy farmers
}

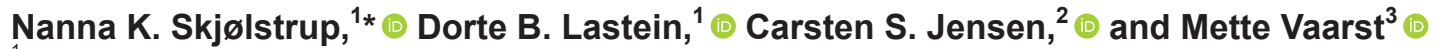 \\ ${ }^{1}$ Section for Production, Nutrition and Health, Department of Veterinary and Animal Sciences, Faculty of Health and Medical Sciences, \\ University of Copenhagen, 1870 Frederiksberg, Denmark \\ ${ }^{2}$ Department of Sociology, Faculty of Social Sciences, University of Copenhagen, 1353 Copenhagen, Denmark \\ ${ }^{3}$ Department of Animal Sciences, Aarhus University, 8830 Tjele, Denmark
}

\begin{abstract}
Limiting antimicrobial use (AMU) in dairy farming is an important step toward reducing antimicrobial resistance (AMR). Therefore, it is relevant to understand dairy farmers' choices and the potential for change in relation to AMU, even in countries with low usage. Furthermore, there is an increasing recognition of the need to focus on both the individual farmer's behavior as well as the context surrounding and influencing the farmer's decisions in relation to AMU if the goal is further reduction. To date, no studies have taken into account both the individual farmer and their context in both conventional and organic dairy farms under Danish conditions. For this study, 15 Danish dairy farmers were interviewed using qualitative semi-structured research interviews, and the notion of landscape was used to describe the context of their AMU. We found that AMR was considered a distant element of the farmers' antimicrobial landscape. Daily challenges such as acutely diseased animals and poor housing conditions seemed more urgent and overruled the threat of AMR. We also found that interviewed farmers had differing opinions on farm management, partly shaped by changes in legislation and ways of farming over time. At one end of the scale, some organic farmers had rethought the current way of farming; keeping robust animals in a natural setting was expected to prevent disease. They were positive about legislation, and the numerous restrictions on AMU over time were thought to contribute to ensuring quality for consumers. At the other end of the scale, some conventional farmers perceived disease as something that should be controlled through treatment, and the currently eased legislation and intensification of farming have legitimatized AMU for this purpose, leading to an expectation among these farmers of certain rights to handle medicines themselves.
\end{abstract}

Received March 31, 2021.

Accepted June 21, 2021.

*Corresponding author: nannaks@sund.ku.dk
These contrasting views might lead to inspiration and competition in terms of reducing AMU, as the farmers appeared to value the opinions of other farmers, and they were found to continuously assess each other. Through such ongoing assessment, pioneers of AMU reduction-whether organic or conventional-might motivate their colleagues to change their AMU. Future research should address the potential of experienceand attitude-sharing among farmers as motivation to reduce AMU.

Key words: antimicrobial resistance, farmer perceptions and choices, societal context

\section{INTRODUCTION}

The use of antimicrobials for both humans and animals has caused a rising global challenge of antimicrobial resistance (AMR; Laxminarayan et al., 2013; Tang et al., 2017). Reducing antimicrobial use (AMU) in dairy farming is therefore one area of importance (WHO, 2015). Despite a generally low level of sales of antimicrobials in Denmark (EMA, 2020), antimicrobial consumption in cattle has been at the same level for the past 5 years, with a slight increase in consumption among calves over the past year (Korsgaard et al., 2020). Therefore, a further reduction in AMU in Denmark is of continued importance. Dairy farmers are some of the central actors when working toward reducing AMU in agriculture. In many countries, dairy farmers administer antimicrobials without having to consult a veterinarian, and it is therefore important to understand the perspectives of the dairy farmer, his or her individual opportunities for and interests in reducing AMU, and the influence of their surroundings (Golding et al., 2019). Qualitative research methods such as semi-structured interviews are appropriate for this purpose, as they allow participants to speak freely about a topic and can thereby uncover important aspects. To date, no such research on dairy farmers' decisions and thoughts on AMU has been conducted under Danish conditions and involving both conventional and organic dairy farmers. 
There is an increasing awareness of the importance of context in trying to understand farmers and their potential to change their AMU, as opposed to a sole focus on individual behavior (Chandler, 2019; Adam et al., 2020; Begemann et al., 2020; Rynkiewich, 2020). The notion of landscape can provide a framework for describing the structures and actors involved in a given context (Ormond, 2016; Tsing, 2017). Based on previous research in the area, the current landscape of AMU in Danish dairy farming is expected to involve different actors, such as consumers, the media, and veterinarians (McIntosh and Dean, 2015; Swinkels et al., 2015; Golding et al., 2019; Wemette et al., 2020), as well as physical settings such as the farm and barn environment (Buller et al., 2015). Furthermore, cultural and political circumstances such as legislation (Fischer et al., 2019) and current discourse on AMR in the media and society (Buller et al., 2015; Golding et al., 2019; Wemette et al., 2020) are expected to influence the antimicrobial landscape. We expect these landscape structures to affect the individual dairy farmer's views and understanding of their situation with regard to AMU.

According to Tsing (2017), a landscape is temporal. It is therefore important to consider the history and developments of the constantly changing context to understand current and future perspectives and actions related to AMU and AMR. An example of a changing context and an important aspect of the antimicrobial landscape could be international farming conditions moving toward centralized, intensified, and increasingly efficient farming (OECD/FAO, 2018; Clay et al., 2020). Similarly, in 2019, Danish dairy production consisted of 566,640 dairy cows distributed across approximately 2,800 farms, delivering 5,614 million kilograms of milk to dairies, of which approximately $12 \%$ was organic. Back in 1993, a slightly higher number of dairy cows were distributed across 6 times as many farms, delivering less milk in total, of which less than $1 \%$ was organic (Statistics Denmark, 2019). Both Danish and international farming conditions have therefore changed, just like the context in which choices about AMU are made.

As evident from the numbers cited, organic farming in Denmark has developed in magnitude over the period. The conditions for organic farming have also changed. The first Danish law on organic agriculture was presented in 1987, followed by multiple action plans and notable economic incentives over the following decade (Halberg et al., 2008). Under Danish conditions, the premium for organic milk is approximately $20 \%$ higher than for conventional milk (Bro, 2021). Internationally, certified organic milk makes up only $0.9 \%$ of the global market, yet the share has been growing over time (KPMG, 2018).
Consumer demand for organic food has increased in Denmark (Statistics Denmark, 2020) due to health, environmental, and animal welfare perspectives (Grunert et al., 2000; Halberg et al., 2008). Furthermore, it has become important to avoid pesticides and medicine residues, which helps to create a positive view of organic production under Danish conditions. Megatrends among Danish consumers go hand-in-hand with this perception of organic food (Halberg et al., 2008). These changes in consumer trends are part of the context Danish farmers must navigate in relation to their AMU. Globally, similar consumer trends have been found to influence farming practices (Haggerty et al., 2009).

Legislation is another important aspect of the Danish antimicrobial context. Since national surveillance was introduced in 1995, all AMU by farmers has gradually and to a large extent been determined by legislation. Elements of AMU control include national surveillance of AMU, antimicrobials exclusively prescribed by veterinarians, thresholds for maximum usage without government supervision, and limitations on the use of specified antimicrobial substances. However, since 2006, conventional Danish dairy farmers have generally been allowed to have medicines available at the farm for treatment of certain defined diagnoses, along with a requirement for regular "obligatory" veterinary visits, the frequency of which depend on the type of veterinary agreement (Ministry of Environment and Food of Denmark, 2018). Farmers can choose between 4 different types of veterinary agreements. Two of these, Module 1 and Module 2, are mostly directed at conventional farmers, as they have more freedom to use medicines on the farm. With a Module 1 agreement, typically chosen by conventional farmers with a smaller number of animals, the veterinarian must initiate treatment for adult cows, but the farmer may finish the treatment course using medicines prescribed by the veterinarian. With a Module 2 agreement, typically chosen by larger conventional farms, the farmer can initiate treatment of defined diseases in all animal groups, but the veterinarian must visit more regularly. The other 2 types of veterinary agreements, known as basis agreements, are often relevant to organic farmers. No extra allowances with regard to medicine use are granted under these agreements; however, the veterinarian only needs to visit once or twice per year, according to the type of agreement (Ministry of Environment and Food of Denmark, 2018).

Organic farmers, by contrast, need a veterinarian to initiate all treatments (Organic Denmark et al., 2020). Furthermore, withdrawal times for organic meat and milk are twice as long as for conventional products, and organic farmers are not permitted to use all of the medicines available on the market (Danish Agricultural 
Agency and Ministry of Food, Agriculture and Fisheries of Denmark, 2018). Danish legislation has changed frequently over time, thereby changing the terms of AMU for all Danish farmers.

Investigating perspectives of farmers with an low average AMU at a national level, here personified as Danish farmers, while reflecting on their context (i.e., the landscape of AMU) might provide new insights into how changes in context can influence farmers' choices, and how to promote future AMU reduction in a global context. The aim of this paper was to explore the antimicrobial landscape from the perspective of Danish dairy farmers. This topic was approached inductively, using semi-structured interviews with Danish farmers to explore their perceptions of AMU and their current practices, as well as opportunities and obstacles in terms of changing this practice. The notion of landscape provided a useful metaphoric tool for structuring, understanding, and discussing the results of the analysis. As a part of this discussion, notable variations in the farmers' landscapes were investigated to further understand the implications of these differences.

\section{MATERIALS AND METHODS}

This project complied with relevant Danish and international standards and guidelines for research ethics, and approval was granted by the Research Ethics Committee for Science and Health, University of Copenhagen (Ref. no.504-0066/19-5000). Furthermore, the project complied with the rules of the General Data Protection Regulation, and approval was granted (Ref. no. 514-0312/19-3000). The study has been reported in line with the COREQ checklist (Booth et al., 2014).

\section{Participants, Recruitment, and Ethics}

A participation matrix of farming type, age, employment status, and gender was created to ensure variation among recruited participants. Inclusion criteria included people working with cattle for commercial purposes and those in charge of the everyday treatment of the animals and treatment decisions. The matrix was filled out using the researchers' professional networks of dairy farmers (i.e., through purposeful sampling) and interviewed veterinarians' (part of a related study) networks of farmers (i.e., through snowball and purposeful sampling). Only dairy farmers without an established relationship with the interviewer (first author) were recruited. Recruitment continued until data saturation was achieved, meaning the time when elements brought up by the interviewees tended to be redundant of what was collected in previous interviews (Fusch and Ness, 2015).
Interviewees were contacted via telephone by the interviewer, who introduced herself as a researcher from the University of Copenhagen interested in the farmer's opinions on AMU in dairy farming, and briefly explained the practicalities before asking whether the farmer wanted to participate. Three of the 18 farmers declined due to time constraints. Before an interview was initiated, every participant signed an informed consent form, thereby agreeing to participate and allowing the transcribed interview to be used for analysis. The informed consent form briefly summarized the project, ensured the participant complete confidentiality, and informed them of their right to withdraw from the interview at any time before data analysis was initiated. No participants withdrew their consent.

\section{Interviews}

Between September and November 2019, the first author conducted all of the interviews using a qualitative, semi-structured approach. Before the interviews, the first author made a declaration of preunderstandings to be able to uniformly and openly meet the interviewees. This declaration included the first author's own background (formerly practicing veterinarian, $\mathrm{PhD}$ student at the time of the study), previous experience with farmers, veterinarians, and the use of antimicrobials, perception of prudent AMU, and expectation of replies from interviewees. The first author had no previous experience of conducting interviews but attended several practical courses in interview techniques and conducted 3 pilot interviews of nonincluded farmers to practice and adjust the interview guide before initiating the interviews for this study.

All interviews were conducted in Danish, at the interviewee's workplace, either in a quiet office at the farm or in the farmer's home, without disturbance from other people. A cozy and trustful atmosphere was sought, to encourage interviewees to speak openly. Interviews followed an interview guide covering 7 themes (Table 1), with a gradual increase in the level of abstraction, lasted approximately $90 \mathrm{~min}$ (range: 75-120 min), and were audio recorded. At the beginning of the interview, interviewees were ensured confidentiality and encouraged to direct the course of the interview themselves. The interviewer was responsible for keeping to the themes of the interview guide. During the interview, any uncertainties or contradictory statements were elaborated upon; the interviewer repeated central statements, and the interviewee confirmed or corrected this interpretation. At the end of the interview, the interviewer performed member checking, giving a brief summary (on average $16 \mathrm{~min}$ ) of main noted key points 
of the interview to give interviewees the opportunity to correct or add any information.

\section{Interview Analysis}

After every interview, the interviewer gave a reflective commentary with immediate thoughts and impressions from the interview, and relevant adjustments were made to the interview guide as part of the iterative process. The first author transcribed all interviews to ensure continuity and in-depth knowledge of the data. Because the primary focus was on the meaning of the interviews, they were transcribed using a non-verbatim approach. Member checking at the end of the interview as well as continued repetition of statements during the interviews to ensure correct interpretation by the interviewer meant that the transcripts was not returned to the participants for further validation.

Transcription and coding were performed using NVivo version 12 Plus software (QSR International; https://www.qsrinternational.com/nvivo-qualitative -data-analysis-software/home/). For the transcriptions, an asterisk $(*)$ was used if names could be easily recognized, square brackets were used to provide explanatory information, and [. . .] was used to indicate where a quote had been shortened. All interviews were analyzed by the first author, inspired by the inductive methodological approach used in grounded theory (Corbin and Strauss, 2015). First, meaning condensates (sequences of statements given a heading in line with the content) were created through open coding; thereafter, axial coding was performed to identify themes across interviews. The approach was not strict grounded theory, even though the codes and themes were identified through an inductive coding process. This was because new theories were not created; instead, the identified themes inspired the use of the landscape framework, as presented in the Introduction. The landscape framework has previously been used within other scientific fields, such as anthropology (Tsing, 2017); in this paper, we found the term useful to collectively describe the identified themes. Coding procedures, the contents of themes, and the meaning of central citations were discussed in the author group, and citations used in this paper were translated to English by the first author. An overview of the coding tree can be seen in Appendix Table A1.

\section{RESULTS}

A total of 15 farmers from different geographical locations across Denmark were interviewed. Participants included 6 organic farmers (2 women, 4 men) and 9 conventional farmers ( 5 women, 4 men). In addition to a relatively even distribution in gender, farmers of different ages and employment status were represented in both faming types. The individual characteristics are described in Table 2. The audio recording failed for one interview (FC10), but the reflective commentary and impressions from the interview still contributed to the results of this study.

\section{Danish Farmers' Antimicrobial Landscape}

Analysis of the transcribed interviews resulted in 6 themes or central landscape structures that formed part of the interviewed Danish farmers' antimicrobial landscape. The landscape structures had different local and global relevance to the interviewees. "The available toolbox for treatments," "the local farm setting," and "the veterinarian - an integrated partner or rare visitor on the farm" were all structures that closely affected the farmers' local and everyday farming environment in concrete and practical ways. Both "legislative structures" and "other influential actors" were on the border of local and distant relevance to farmers, whereas "antimicrobial resistance as a distant element" was an abstract term present in a more global context. Every interviewed farmer had their own individual view on the landscape, and the spectrum of individual perspectives collectively described the common antimicrobial landscape of the interviewed Danish farmers.

All landscape structures will be explored in the following sections. They will be elaborated and nuanced with a starting point in the individual interviews (iden-

Table 1. Themes of the interview guide used in the interviews, on interviewed Danish farmers' antimicrobial landscape

Interview guide

- The last treatment at your herd (motivation, course, decisions, communication)

- Collaboration with veterinarian (format, motivation, changes)

- Medicine use in your herd (responsibility, goals, experience of antimicrobial resistance)

- Knowledge of antimicrobials and resistance ("correct antimicrobial usage," information sources, antimicrobial resistance)

- Attitudes about antimicrobial usage (own, society's, colleagues', veterinarians', employees', advisors')

- Change in antimicrobial usage (motivation, future use, ways or methods to achieve this)

- Surroundings (systems, legislation) 
Table 2. Individual characteristics of interviewees

\begin{tabular}{llllll}
\hline Identity $^{1}$ & $\begin{array}{l}\text { Type of } \\
\text { farming }\end{array}$ & Gender & Age & $\begin{array}{l}\text { Employment } \\
\text { status }\end{array}$ & $\begin{array}{l}\text { Farm size } \\
\text { (no. of cows) }\end{array}$ \\
\hline FO1 & Organic & Female & $<40 \mathrm{yr}$ & Employee & 120 \\
FC2 & Conventional & Female & $<40 \mathrm{yr}$ & Owner & 95 \\
FO3 & Organic & Male & $<40 \mathrm{yr}$ & Employee & 150 \\
FO4 & Organic & Male & $>40 \mathrm{yr}$ & Owner & 210 \\
FO5 & Organic & Female & $>40 \mathrm{yr}$ & Owner & 220 \\
FO6 & Organic & Male & $>40 \mathrm{yr}$ & Employee & 160 \\
FO7 & Organic & Male & $<40 \mathrm{yr}$ & Employee & 580 \\
FC8 & Conventional & Female & $<40 \mathrm{yr}$ & Employee & 310 \\
FC9 & Conventional & Male & $<40 \mathrm{yr}$ & Employee & 220 \\
FC10 & Conventional & Male & $>40 \mathrm{yr}$ & Owner & 390 \\
FC11 & Conventional & Female & $>40 \mathrm{yr}$ & Owneyee & 430 \\
FC12 & Conventional & Female & $>40 \mathrm{yr}$ & Employee & 390 \\
FC13 & Conventional & Male & $>40 \mathrm{yr}$ & Owner & 190 \\
FC14 & Conventional & Male & & 250 \\
FC15 & Conventional & & & 330 \\
\hline
\end{tabular}

${ }^{1} \mathrm{~F}=$ farmer; $\mathrm{O}=$ organic $; \mathrm{C}=$ conventional.

tified as FO1 to FC15 for organic and conventional farmers, respectively). Selected citations from these interviews will be used to exemplify important aspects.

\section{Local Structures of the Antimicrobial Landscape}

Theme 1: The Available Toolbox for Treatments. Starting with the farmer's local context, an important structure of the antimicrobial landscape involved perspectives about concrete and practical treatment situations: when an animal should be treated, how it should be treated, and for how long. Decisions about these questions were influenced by the interviewees' thoughts on the "correct use of antimicrobials" and the type of available medicines (including treatment methods that were alternative to antimicrobials). We chose to use the metaphor of the "toolbox," covering both the spectrum of available substances and methods to treat with, as well as perceptions and the given legislative framework, because every treatment substance or method was guided and determined by this and could therefore not be seen separate from it. Therefore, we call it "the available toolbox."

"Penicillin" was used as a common name for antimicrobials in most interviews. The farmers did not distinguish between types of antimicrobials, and "penicillin" was used as a synonym for all classes of antimicrobial substances. Furthermore, a misunderstanding of broad-spectrum antimicrobials was evident from the interviews, as that Penovet (benzylpenicillin procaine) was an example of a broad-spectrum antimicrobial, due to its application for many different types of diseases, which is why it was perceived by the interviewed farmers to be inappropriate to use as a first choice.

As mentioned in the Introduction, an extended set of rules governing medicine use apply to organic dairy farmers. These additional legislative rules added an economic layer to decisions about treatment for the organic farmers. Some organic farmers indicated that they preferred antimicrobials administered in a way that could ensure as short a withdrawal time as possible, due to the double withdrawal time applying for treatments in organic farming. This preference was also mentioned by a few conventional farmers. For example, the withdrawal time could be more than halved if some types of antimicrobials were given intravenously instead of intramuscularly. This has led some organic farmers to request certain methods of administration from their veterinarian. Furthermore, the value of a diseased animal was considered carefully before the veterinarian was contacted. The chances of a sick calf being treated at the weekend was therefore poor, as prices for veterinary assistance are often highest out of hours. Interviewee FO6 described how leftover medicines originally prescribed for another animal could even be used for the sick calf to avoid veterinary expenses (or killing the animal), an action that is not permitted according to Danish legislation: [FO6] "We had received some medicines [from the veterinarian] to complete treatments when we had some other calves treated. Then, at the weekend, I could treat a calf with fever. . . However, if we had not had any medicines... it's too expensive to call the veterinarian in terms of the value of the calf. Then it's actually better to euthanize the calf. That is bad, actually."

Some organic farmers wanted to reduce their use of what they perceived as "unnecessary AMU," also referring to financial considerations. Instead they used alternatives to antimicrobials, as explained by farmer FO4 in the case of mastitis: [FO4] "We don't treat any mastitis cases .. Actually, that's not true; we can treat an [Escherichia] coli infection, and a first-parity cow, but 
these make up less than ten cases annually, so as good as none. Anyway, our strategy is not to treat mastitis. Instead, we use peppermint lotion and perhaps painkillers. However, we do not often use painkillers for a regular mastitis case [. . .]." In addition, the use of antimicrobials for dry cow therapy could be less frequent for some organic farmers who perceived this type of treatment as prophylactic: [L7] "It is very rare [that we use dry cow therapy]. I think . . I I don't know, perhaps once or twice annually, but not often. I know that my boss dislikes the fact that some farmers regularly take milk samples and more or less treat the cows preventively at dry-off."

An acute mastitis case would be managed completely differently in FC15's conventional herd, where treatment with antimicrobials was initiated to relieve pain and discomfort regardless of the stage of lactation: [FC15] "I don't want to have a sick cow walking around that I can't treat. That's just how it is. If they have a fever, they will be treated. Whether or not it's mastitis and whether the cow will be dry in 2 months or 14 days. That's how I feel, and that's what I have told the veterinarian*. [Mimics the veterinarian] 'Well, you gain nothing from that [treatment], the cow will have recovered in 3 days anyway.' Well, that may be, but that's how I want it."

Medicines and treatments appeared to be a more obvious choice for many of the interviewed conventional farmers compared with the organic farmers. The consequences of antimicrobial treatment were not as wide-ranging as for organic farmers, as there were few expenses and the medicines were available. Farmers talked about the "correct use of medicines" differently: it could mean either timely intervention or delaying treatment for a few days in some cases, as until the disease had developed further or a diagnostic answer was available. This was described by FC12: "Well, sometimes I delay treatment for a day. Perhaps I'll try giving the calf water with sugar, and I am very attentive toward it [. . .] What if I can't feel anything at the umbilicus that day? We want to use as little penicillin as possible, so sometimes we might delay for 1 day so that we are better able to correctly diagnose the calf. Then I won't need to treat with one type [of antimicrobial] and then change it." This makes it easier to choose the correct antimicrobials according to the diagnosis. The correct duration of treatment course was also highlighted as important by some farmers.

Some organic farmers placed great value on naturalness and robustness. The idea was to ensure robust animals so that disease and treatments could be avoided, as elaborated by FO3: "If an animal is sick, it should leave this herd. It is a weak animal and not one we should breed from [.. .] Nowadays, farmers only breed animals that are expensive to keep and need a lot of attention in relation to medicines, feed, and all kinds of things [. . .] When I am in charge [at this farm], the animals will be my tool to maintain our ecosystem. The cows' purpose is to harvest the grass and make sure it's kept at the right growth stage. Then you need cows that will stay healthy when they are only fed grass and not all weird kinds of feed [. . .] Cows are meant to eat grass, so they should not be fed anything else." In addition, other organic farmers expected that letting the cow and calf be together as nature had intended would ensure a sufficient transfer of immunoglobulins from cow to calf.

Some organic farmers also talked about the "correct use of medicines" with some of the same phrases illustrated previously: for example, the belief that the treatment course must be finished, and using the argument "sick animals need treatment." This was exemplified by FO6: "There are many farmers trying to avoid even the smallest amount of medicine. I don't agree with that. I believe that if you are sick, you should be treated in order to recover. I think that discomfort goes against the idea of animal welfare. That's my point of view. However, there are some farmers who have the opposite opinion, who think we should avoid treatment as far as possible." However, finishing the course of treatment could conflict with some of the previously mentioned limitations for organic farmers, such as extended withdrawal times and veterinary costs.

Both organic and conventional farmers used alternatives to antimicrobials, but for the organic farmers, alternatives represented an opportunity to treat where veterinary assistance could be avoided. Furthermore, organic farmers mentioned a larger variety of alternative products, such as active coal, electrolytes, acidifiers for calves' milk, homeopathy, and peppermint lotion, and teat amputation or drying off single teats in cases of mastitis. Conventional farmers used other alternatives, such as water with sugar for calves and peppermint lotion for subclinical mastitis cases. Both were used as tools to postpone (or perhaps avoid) treatment.

It became evident through the interviews that individual farmers perceived the "correct use of antimicrobials" differently, as in the case of diverging perceptions of the optimal duration of treatment. Furthermore, a wide range of approaches to, for instance, the treatment of mastitis - both acute and subclinical - were presented. Different farmers perceived each of the approaches to be the "correct" approach. However, all farmers believed the available toolbox for treatments was entangled with legislation, personal attitudes to pain and discomfort and the control thereof, social norms in relation to their own perception of colleagues' treatment choices, and veterinarians' attitudes toward treatment. These were all important aspects and structures of their antimicrobial landscape. 
Theme 2: The Local Farm Setting. The local farm setting was another important structure of concrete and practical relevance in the interviewed Danish farmers' antimicrobial landscape. This included the physical framework as well as the economic status of the farm.

Some framework-dependent challenges were revealed, such as housing conditions, which could make it difficult for both conventional and organic farmers to live up to their own perception of the "correct use of antimicrobials." For example, poor ventilation was assumed to result in cases of pneumonia and mastitis in the warm summer months. The issues with poor ventilation was exemplified by FC14: "We have groups [of calves] that are not that big, and then three get pneumonia. You think: well I can treat the three with pneumonia today and then wait two days to treat the three other calves. Or I could treat all six at once. It's probably not correct, but it's the solution being used. I have seen so many times what happens if I don't do it that way ... I know that it's scientifically incorrect." It is difficult to regulate temperature and ventilation in old cowsheds, and this poses a challenge to young calves in particular. In addition, not being able to clean the boxes properly before introducing a new group of calves due to overcrowding was also mentioned as a considerable challenge. Interviewee FC2 illustrated how this was handled: "[. . .] For example, when the calves go from individual housing to group housing, I treat them for coccidiosis. I think it's mostly a safety precaution because he [the veterinarian] thought we should try to avoid it. So we did-we tried it, but I thought our calves became ill at once. Now, we don't need to discuss it anymore. Our level of medicine use is generally very low, so we just accept that this is the way it is. We have tried not to [treat], and the calves did not look as good as they do now." The farmer may have accepted loosening the safety net (the preventive treatment) for a period but experienced an increase in disease frequency and felt a loss of control. The fact that the farmer had attempted to change the conditions and at the same time perceived the general treatment level of the farm as low appeared to justify the present state of affairs.

Some organic farmers wanted to provide the animals with less restrictive "physical frameworks" and related this to considerations of robustness. In their view, the animals should be able to manage in the physical setting and, for instance, eat their original natural feed, such as grass, which was thought to strengthen the cow's immune system. Furthermore, being out on pasture allowed the cows to move away from their own manure, which was not possible inside a cowshed. Farmer FO1 described this notion: "[. . .] You need to think about the production - what kind of animals you have, how they are built according to digestion and processing of food, and therefore which feed they should have. This approach will help you go a long way. It might be that you need to accept that the yield will reduce slightly and that you can't push your animals as hard. [. . .] The problem is that you [in the farming society] have a strategy where everything is pushed to the limit, where you push the cows that much that it takes very little before some of them break down. I don't believe in this strategy."

Some organic farmers questioned the way animals are kept in the majority of herds today - for instance, with animals housed inside all year round and fed a variety of high-density feed. Instead of thinking about solutions within the current framework, they used the animals' natural behavior as inspiration to dream about a future with robust animals in a natural setting without production or framework-dependent diseases. However, this seemed to be a compromise with the current milk yield.

Some organic farmers were also thinking about solutions within the current framework, such as seasonal calving, where the most valuable calves were born first and thereby got housed in clean pen conditions with a low infection pressure, as explained by FO4: "[. . . It's easy with the calves. We only have Jersey calves in August and the beginning of September. When we have our Jersey calves, the calf housing area is empty; it has been burned, disinfected, and washed. Furthermore, it has been empty since May 1 [. . .]. It runs smoothly for six to ten weeks before cryptosporidiosis enters." Furthermore, they controlled access to pasture, to avoid having cows outside on warm summer days. They achieved this by allowing access to pasture at nighttime during the warm periods.

Some farmers reflected on how the framework of the current production negatively affects the animals. The occurrence of cryptosporidiosis was expected in light of the housing conditions, and the increased feeding levels and concurrent higher milk yield resulted in a higher frequency of diseases, as elaborated by FO4: "Back in the days when we had a lower feeding level and lower milk yield, [E. coli mastitis] was not a problem [. . .]. Now we push the cows a little more, and as a result. . . they probably yield a bit more than 10,000 $\mathrm{kg} E C M$, and then it starts to get a bit trickier."

A high milk yield therefore seemed to be incompatible with keeping robust animals. Some interviewed farmers perceived that healthy animals would yield more, but only to a certain degree. Above this limit, the animals were pushed too hard, were stressed, and yielded less, as described by FO4; FO8 also described this balance: "What I found most awful this summer was the fact that you could see all the high-yielding cows going down; they couldn't manage. Despite this, we all fight to achieve a 
high-yielding herd. However, I also believe in balance, where you can say: the cows have a high yield, but they also have good health. That's what I want-I want a healthy high-yielding cow, if that's possible."

The physical framework could also challenge farmers' chances to live up to their own standards of AMU on a daily basis. The economic status of some herds forced farmers to use existing cowsheds, which posed a challenge to herd health during certain periods. The local farm setting was therefore a rather fixed structure in the antimicrobial landscape for longer periods of time, shaped by economic and structural development, weather conditions, and the farmers working there. The way these challenges were handled varied between organic and conventional farms. Some organic farmers had taken the consequence of the negative effect of the physical framework on their animals. They had started to think about alternative production conditions, either within the current framework or by taking a starting point in the natural behavior of cows.

Theme 3: The Veterinarian-An Integrated Partner or Rare Visitor on the Farm. Another structure that seemed important to the local context of the interviewees' antimicrobial landscape was their veterinarians' role in the herd. Large differences were revealed in the use of the veterinarian within both organic and conventional herds.

The incentive to extend the use of veterinary services through veterinary agreements is different for organic farmers. Due to legislation, they are not able to have medicines available on the farm. Nevertheless, the veterinarian could play a central role in optimizing an organic herd. For organic farmers, having a veterinary agreement and herd health consultancy was an active choice often accompanied by the desire for antimicrobial-free production. The veterinarian entered as an active co-player the minute that antimicrobial-free production became the goal: [FO7] "We are dreaming about getting to a point where we don't need antimicrobials at all, or at least to greatly reduce the need. We are at a low level of use already, which makes me think that when we try to do so, the whole world will look at us like... if we don't treat our animals, they must be mistreated, they must suffer, many things must be wrong. Therefore, I made an agreement with my veterinarian that they should come every Monday and Thursday to start with, but there wasn't much for them to look at. Now they come every Monday."

In other organic herds, a focus on naturalness and robustness gave the veterinarian a withdrawn role, where they just administered treatments or acted as "firefighters," accessing the herd once the damage had been done. Veterinarians were not perceived as helping with preventive measures, and they were not expected to contribute within that area: [FO1] "[. . .] Because my focus is less on treatment and more on prevention. . . I'm not expecting that from him [the veterinarian]. It's probably because you traditionally see the veterinarian as someone who treats animals, not so much within the preventive area. Then again, there is vaccinations, etc. . .." The veterinarian's lack of insight and understanding about the farmer's way of farming was perceived as increasing the separation in their collaboration. Instead, farmers gained experience-based knowledge from other organic farmers in similar situations.

Some conventional farmers described having gradually withdrawn from veterinary assistance, with the exception of that required by law (e.g., herd health visits every 1-2 wk and the administration of certain types of medicines) and skilled work they had not yet mastered themselves: [FC11] "I get veterinary assistance for digestion disorders and metabolic diseases [ketosis, abdominal displacement] - things that need to be listened to [with a stethoscope], perhaps rumen motility or if the abomasum is correctly positioned . . . Ketosis I can diagnose myself with a strip - that's easy. Overall, it's just the skilled work with the stethoscope; all the things I am not capable of myself that I need help with. Diagnosing a milk fever-that's not [difficult] . . . If it has mastitis, metritis, or whatever it is . . Basically, it needs to be something - perhaps reproduction-that I'm not able to feel myself-if there is something wrong with the ovaries. Those are the kind of things I need help with."

However, the routine tasks related to a herd health visit and the frequent conversations about the herd were of great importance to some farmers. The veterinarian was seen as a collaborative partner who had a lot to say regarding the development of the herd: [FC15] "There is something about second opinions and the daily contact with him [the veterinarian]. The daily sparring partner. The world is not changed on a weekly basis, but it's often a matter of just discussing whether or not we are on the right track [. . .]. It's all about being able to benefit from his experience. The fact that you get someone with an extensive background knowledge and experience to push things in the right direction."

The need to change AMU was negotiated between veterinarians and farmers. For example, changing from broad-spectrum antimicrobials at herd diagnosis (diseases that farmers are allowed to treat on their own) to narrow-spectrum antimicrobials. In some situations, the farmer led the way toward a change in AMU based on new knowledge: [FC11] "Yes, it was the veterinarian who started with it [use of Eficur, ceftiofur hydrochloride]. I knew nothing, back then when we started with herd health consultancy. I guess we started it in 2009. 
Back then, I didn't know . . . Eficur, 0-day withdrawal [for meat and milk] - that was convenient. When they started writing about the need to reduce $A M U$ in Kvægnyt [farmer magazine], well . . . it took probably 2 years to convince the veterinarian that we should reduce the use [of Eficur]. I asked him if we could change it to Penovet instead, and he responded: 'You can save a lot of milk due to the withdrawal times!' I argued with him, and he's changed it now."

In other situations, the veterinarian reduced the number of treatments by ending the use of intrauterine antimicrobials for treatment of retained placenta and metritis, as described by FC9: "When we started I was skeptical. I know they get antimicrobials in their body as well; however, the fact that you have had your arm inside her [to remove the placenta] . . . I know that I'm not supposed to do it, but . . . I thought it would be nice to be able to leave some antimicrobials inside them [. . .]. At the time, they started talking about how the antimicrobials actually just ended up in the drain, it made more sense [to stop]. Actually, it works fine." Furthermore, AMU was reduced by using vaccination instead of treatment in some groups during periods with high disease frequency, or by changing the treatment limits for mastitis cases during lactation. This meant that cows with mastitis at the end of lactation were not treated, which, in some herds, included both acute and subclinical cases.

Veterinarians' roles in the interviewed Danish farmers' antimicrobial landscape varied, as did their importance in the daily decisions about treating sick animals. Regardless of the type of production, the veterinarian could be seen either as a vital partner or as a mere necessity for the legally required duties in the herd. The veterinarian's work could also change over time if new conditions arose in terms of the framework for the collaboration, such as changes to the type of production or the veterinary agreement.

\section{Border Structures of the Antimicrobial Landscape}

Theme 4: Legislative Structures. Current legislation was another central structure of the interviewed Danish farmers' antimicrobial landscape, due to the long history of regulations, as described in the Introduction. Legislation was of local relevance to the farmers, as it determined their everyday actions, yet it was also a distant structure, as the drawing up of legislation was out of their hands.

Some conventional farmers wondered how lines were drawn according to which types of medicines they were allowed to handle. Furthermore, farmers wondered why they were not able to treat a cow with milk fever more than once. Among some conventional farmers, an increased feeling of ownership and need to take over responsibility in relation to the administration of medicines could be seen. Dealing with antimicrobials and related decisions on a daily basis gave them a sense of independence, decoupling the veterinarian, as explained by FC13: "Nowadays, when we administer treatments ourselves, it's fair to say that we are more competent at giving injections [than the veterinarian]." Another farmer saw himself as the most experienced in relation to his own herd, and treated animals outside of the defined diagnosis and therefore the legislative framework. The availability of medicines and the right to treat animals early in the course of the disease seemed to boost this behavior: [FC11] "[. . .] I had a cesarean section performed the other day, and now the cow has a slight fever. Should I call the veterinarian to treat it, or should I just treat it myself with some Penovet? However, it doesn't fit inside a frame [defined diagnosis]. Should I then call it metritis? That's probably the closest fit."

Some of the interviewed farmers who changed from conventional to organic farming (e.g., in relation to a change of job or reorganization of the herd) thought that the organic legislation belittled the farmer. This was because they had previously been able to diagnose and treat their animals but, as organic farmers, were no longer allowed to do so: [FO3] "Yes, when you become an organic farmer, you automatically become less intelligent! You're not allowed to do anything anymore. For example, if you have a sick calf you can normally treat it, but if you're organic - no, then you're not clever enough to realize that your calf is sick, and you need to call the veterinarian in order to treat it. I would say that organic farming takes your freedom away to some degree. I feel like we are regarded as less competent farmers. There are many extra rules because we are not capable of doing this and that, and then someone needs to come and supervise us." It seems that the allowance to handle medicines independently gave some farmers a feeling of freedom; having this freedom taken away due to the restricted organic legislation caused frustrations and was perceived as a lack of societal trust in their competencies.

The organic farmers who had never been involved with conventional farming perceived the organic legislation differently. They saw it as a necessity that should outwardly ensure quality and differentiate the organic product for consumers: [FO7] "I'm actually okay with it [the legislation] as it is. Sometimes you think it would be easier if you could treat that cow on your own ... Or we have a cow with milk fever on a Sunday morning and need to call the veterinarian. . It costs more than 2,500 DDK-for 15 minutes of work. It makes me think that 
I could easily have done it myself. That being said, it's also true that consumers trust organic - they know what [medicines] have been used on this property. They know what this animal has been treated with."

Acceptance of the legislation could also be identified among conventional farmers, due to aspects related to food safety. They recognized the need to document and register all medicines used so that milk and meat should be free from antimicrobials and the dairy and meat industry can stand on target for AMU. Furthermore, they recognized that legislation regulated behavior in terms of AMU: [FC12] "Yes, it might be that we need to register our use of penicillin and that they keep an eye on us. However, it's also okay that we're not allowed to treat like crazy ... To think: this cow is developing mastitis, and if I treat it right away, it can be milked with the rest of the herd even faster." Besides these elements, some conventional farmers understood a kind of tradeoff between the availability of drugs and the demand for documentation. Along with the freedom to treat animals themselves, and thereby the chance to alleviate pain quickly, came the duty to register treatments and the use of medicine.

However, a feeling of frustration accompanied this acceptance. For example, the requirement to register all treatments and use of medicine down to the last milliliter: [FC9] "Of course they [Danish Veterinary and Food Administration] need to supervise us. Luckily, it's been a long time since they were last here. However, they have recently visited some of the herds out here, where I think they were too thorough regarding the medicine [registrations] . . . they're not even allowed to deviate by $2 \mathrm{~mL}$... It's difficult to use that medicine bottle sometimes; you almost need to put it all in syringes to know the actual amount." In this case, the farmer expressed frustration about the perceived unfair requirements for detailed documentation. Greater flexibility and trust in the farmer's good intentions during supervision was requested.

The existing legislation influenced the farmers' daily life to a large extent and was an important structure of their antimicrobial landscape, as the legislation determined their room to maneuver in relation to AMU. For organic farmers, the legislation had become a way to differentiate themselves from conventional farming. They described low treatment rates, which gave the consumer a reason to choose their organic product. Differences in the legislative framework depending on the type of production and veterinary agreement could frustrate some farmers who had experienced changes in the rules that applied to them. Farmers with veterinary agreements allowing the most freedom in relation to medicines use (e.g., Module 2 agreements) could see an increase in the use of medicines and a perception of the right to treat as a matter of course. In contrast, farmers experiencing more imposed restrictions could perceive this as being due to insufficient professionalism and as a sign of mistrust from society.

Theme 5: Other Influential Actors. Another central structure of the interviewed Danish farmers' antimicrobial landscape was the influence from various actors besides the veterinarian. This included colleagues (other farmers), who had a more local relevance in the antimicrobial landscape compared with consumers and the media, who influenced from a distance.

\section{Farmer Colleagues}

Farmers often expressed clear attitudes toward the way other farmers managed their farms. Conventional farmers accused organic farming of compromising animal welfare due to the limits on treatment: [FC11] " $I$ have some organic colleagues. They have a completely different attitude toward treating animals because they are organic farmers for economic reasons [organic farmers are paid higher milk prices], and I sometimes wonder why they don't treat a specific animal. However, the alternative appears to be the captive bolt gun. You get that sense when they discuss what it costs to treat an animal. In relation to mastitis - I couldn't relate to their treatment argument a few years back, but now I understand: it doesn't make sense to treat every mastitis case. However, when they don't treat metritis or other diseases where the cow has a fever and becomes ill, then I disagree ..." In this statement, FC11 implied that organic farmers had varying motives for choosing organic farming, one of which could be an economic incentive due to the higher price for organic milk.

By contrast, organic farmers articulated a constant assessment of their way of farming by the outside world, including their conventional colleagues: [FO7] "The best inspectors we have are our conventional colleagues! For better or worse, without anything negative being said. [. .. They are not controlling us in a direct sense, but you can be sure they're keeping an eye on us."

A perception was expressed by some organic farmers that conventional farming had a higher use of medicines. Increased access to medicines made it easier for conventional farmers to treat, and treatment was described as something anticipated and a fixed part of the herd routines: [FO1] "I think other farmers have much more systematized treatments - it's part of their routines. In that way, it's not an extra workload. [. . .] I think it's just an aspect of the business - they set aside resources for treatment." Farmer FO7 also implies a higher level of medicine use among conventional farmers: "I don't 
want to expose anyone, but it's easy when the medicine bottle is right there on the shelf. We always treat when we have a sick animal. [. . .] I don't mind that I'm not allowed to treat independently. Again, it's important to distance ourselves from conventional farming. It's about gaining the consumer's trust, and we can never breach that, or we would not be able to maintain our higher prices." This illustrates what motivates some organic farmers to leave the treatment to the veterinarian: it has become a way to differentiate themselves from conventional farming and thereby demand a higher price for their products.

Despite being accused of poor animal welfare, organic farmers were of the opinion that they were pioneers when it came to high animal welfare: [FO4] "I believe that my animals are well. I'm happy to walk through the cowshed, and I'm happy to go to them in the field. I think they have a decent life. Furthermore, I enjoy being an organic farmer and being a pioneer in relation to animal welfare. I'm in no doubt that that's what organic farmers are."

\section{Consumers, Citizens, and the Media}

Both organic and conventional farmers were concerned about consumers and their attitudes. Some organic farmers perceived the consumer as an active co-player, helping to define the development of organic farming through their consumption habits and attitudes: [FO7] "We don't want consumers to have any doubts. It's the same with our meat sales* . . We have a standard organic production system, but I also have a smaller property with beef cattle on pasture. It's simply because consumers expect animals* to be out on pasture, so then we need to follow that."

Some conventional farmers perceived consumers negatively, as people who lacked knowledge or were judgmental, which caused frustration. This skeptical attitude toward the consumer could also be found among organic farmers. The perceived lack of knowledge, interest, and understanding of the reality of farming in particular gave rise to frustration, especially if consumers' distorted perceptions and wishes led to new requirements from, for instance, the dairy company, and the farm had to adjust their production to meet what they believed to be meaningless demands.

However, farmers also described a common positive experience in terms of visitors when conventional and organic herds open their doors, as on "Open Farm Day" or "Organic Day" - events where citizens are invited to the farms. Farmers viewed visitors positively when they were open to understanding the farmers' reality and a constructive dialog developed. This was experienced by
FC11: [About "Open Farm Day"] "There was actually a cow that had just had surgery for abdominal displacement, and people realized it was sick-but it had had surgery and had therefore received help, so that meant no further debate was necessary. It was all there was to notice because the rest of the herd looked fine, so there was nothing to debate."

The media's interpretation of farming seemed to preoccupy conventional farmers to a large extent. This gave rise to frustrations due to a perceived unwillingness to understand the reality of farming, as described by F9: [About overuse of medicines in farming] "However, when I hear about it in the media, and they just keep on talking about it-it makes me mad! It annoys me-they should come out here! See what things are actually like . . . That we do not treat like crazy because we feel like it. The authorities watch us thoroughly, as we need to register all use. If anyone thinks we use too much, they will tell us so [. . ." Politicians' and the media's portrayal of the farming industry being responsible for AMR was also mentioned. This has contributed to the spread of misinformation, and the lack of research and understanding of the topic frustrated the interviewed farmers.

One conventional farmer who had reduced their use of antimicrobials had a positive attitude toward the potential role of consumers and the media, who could assist in spreading a positive story to inspire others, a motivating factor for the farmer: [FO8] "I often hear about people who say that we fill our animals with medicine. However, I don't think we do-not at all. I would very much like to get that story out: 'Listen to me, you can have a whole herd, 600 animals in total, and we use this much [indicates zero with fingers] medicine. That's because the animals are thriving and are in great health.' That would be awesome. If we can, then everyone else can too!"

The actors mentioned in this section and their influence had varying degrees of local relevance to the farmers and their antimicrobial landscape. The way colleagues manage their farms and their own attitudes toward that affected many farmers' daily decisions, as in relation to treatment options. Consumer and media attitudes toward and portrayals of dairy farming had a more distant influence, and farmers did not have the opportunity to change these attitudes directly. One exception was on "Open Farm Days," when farmers could enter into a direct dialog with consumers. This dialog presented an opportunity for the farmer to explain about his or her own reality and thereby influence the consumer's perception of dairy farming - a perception that, according to farmers, is often characterized by misunderstandings and a lack 
of knowledge. However, some organic farmers also perceived the consumer as a collaborator who should be listened to and followed.

\section{Distant Structures of the Antimicrobial Landscape- Theme 6: Antimicrobial Resistance as a Distant Element}

Perceptions about treatments remained concrete to most farmers, and this was something they considered on a daily basis, unlike AMR, which was a distant element of their antimicrobial landscape. Not all farmers necessarily understood the term "antimicrobial resistance," and a certain discourse was created when AMR was talked about in popular terms, shaped by the way veterinarians or the media spoke about it. Common to both organic and conventional farmers was the perception of the global threat of antimicrobials and AMR as not being applicable in their local reality. Resistance was thought of as being "from somewhere else," and not from one's own herd: [FO6] "We do have some problems with that thing [AMR], which we should avoid because it's dangerous if you can't treat an infection in your body. Therefore, we need to look out for it. It's good to focus attention on it, but in general, I hope people only use what is necessary."

The risk of resistance was talked about in abstract terms, but some farmers redirected it to concrete actions in the herd. For example, one farmer was motivated to use fewer antimicrobials in the herd, which resulted in the implementation of concrete solutions to reduce the risk of AMR. This included delaying or avoiding treatment for cows with retained placenta that showed no clinical symptoms, and limiting AMU for subclinical mastitis by using only intramammary (instead of both systemic and intramammary) treatment. However, the farmers did not expect AMU in farming to be of importance in relation to the general development of AMR: [FC12] "[. . .] It is concerning if we suddenly can't treat really sick people in need of treatment. However, I think most farmers, on the whole, are careful [. . .]." This statement implies that resistance is an abstract threat, not present in the farmers' local reality. Nevertheless, popular sayings, such as "You should only use the necessary amount" and "We should try to avoid treatment," used the distancing terms "you" and "we," not "I."

Other countries, such as the USA and New Zealand, were mentioned as countries with more pressing issues related to the risk of developing resistance: [FO4] "I don't think there are any Danish farms where resistance is a big issue compared to the food we import. . . I remember my way of handling penicillin and animals in
New Zealand was markedly different from what I experience here." The fact that other countries consume more and have greater issues with resistance seemed to be a reason to accept the current Danish conditions.

In addition to pointing the finger at other countries, Danish swine production and veal calf production were also highlighted. They were accused of struggling to stay below the legal limit for AMU and of use of herd medication, which has a tendency toward prophylaxis, which is not permitted according to Danish legislation: [FC15] "The swine farms have acted against their own interest by using medicines the way they do . . By using herd medication and such. Prevent with medicines, penicillin. I don't agree with that; it's risky and resistance can develop. However, we don't do that in cattle farming. Of course, we can do many things in relation to prevention and hygiene. However, ... I need to be careful what I say, there might be a few veal calf producers who use herd medication. I won't defend what they do. However, that's not happening here. We use penicillin at dry-off for many cows because our cell count is high. We would like to get below 150,000-that's our goal. We are aiming for that; we have got down to that number, and we should be able to again. That's why we have chosen to go all-in on dry-off treatments for a time, to see if we can get down there again." The farmer did not perceive his own actions, blanket dry cow therapy, to be herd medication. The farmer perceived the treatment as temporary and tried to explain the complexity in the herd's challenges with mastitis and the need for blanket dry cow therapy. The farmer seemed to think that these conditions justified an intensified use of antimicrobials over a limited time period, thus distinguishing it from more strategic AMU on a general basis in veal or pig farming.

A focus was also placed on hospitals and doctors in terms of their AMU. They were accused of prescribing unnecessary antimicrobials to humans and to a larger extent than within livestock: [FC14] "I just think that if you look at medicine use in humans compared to animals, I think you'll be surprised. Humans get a lot of medicine. You only need to be at the doctor's for five minutes before they prescribe something for you."

In contrast to perceptions about treatments, perceptions about resistance remained abstract in most farmers' antimicrobial landscape. It seems that AMR is something that "other people" should be concerned about, where "others" could include dairy farmers in other countries as well as farmers in other industries such as swine or veal calf production. Furthermore, doctors' use of antimicrobials was perceived as an even greater challenge in relation to the development of resistance. 


\section{DISCUSSION}

This study explored the antimicrobial landscape from the perspective of interviewed Danish dairy farmers. In particular, legislation appeared to be a prominent structure of the landscape, influencing everyday treatment decisions and defining the collaboration with the veterinarian. Furthermore, depending on the type of production, farmers approached disease differently. These findings highlighted the importance of taking context into consideration when investigating dairy farmers' AMU practices and perspectives. To our knowledge, no such holistic investigation of Danish dairy farmers' AMU has been conducted before.

One of the central findings of the interviews was the variation among farmers in their perception of what "correct AMU" is and when a sick animal requires treatment. Previous studies have found that fewer cows were treated with antimicrobials at organic farms, suggesting a different attitude toward "correct use of antimicrobials" (Bennedsgaard et al., 2003; Zwald et al., 2004; Habing et al., 2016; Krogh et al., 2020; Olmos Antillón et al., 2020). As previously identified by Vaarst et al. (2002), the definition of a sick cow could vary from farmer to farmer, depending on the farmer's perspective and the situation of the herd, which was similar to the interviewed farmers in this study. According to the interviewed farmers, the landscape structures influencing their perspective on "correct use of antimicrobials" included legislation, type of production, and different actors, such as veterinarians and other farmers. Other studies have found that the opinions of other farmers and the herd veterinarian affected farmers' treatment choices (McIntosh and Dean, 2015; Swinkels et al., 2015; Doidge et al., 2021). Similarly, the farmers interviewed here seemed to continually reflect on their own treatment choices, especially in relation to other farmers' choices - either as a way for the farmers to distance themselves from other farmers or as validation for their own choices.

The influence of type of production (i.e., organic or conventional) on treatment decisions has previously been investigated. Vaarst et al. (2003) interviewed farmers who had recently converted to organic farming about their treatment choices in relation to mastitis. Converting to organic principles, as such, did not result in a change in treatment, but new legislative conditions such as veterinary assistance for all treatments resulted in changed management and treatment thresholds for financial reasons. This finding was confirmed under Swedish conditions (Emanuelson et al., 2018) and by some interviewed farmers in this study: the legislative rules for organic farms resulted in a different available toolbox for treatment. However, in contrast to the findings of Vaarst et al. (2003), some of the organic farmers interviewed in our study seemed to have different opinions about treatment shaped by more than just economic considerations. This mindset allowed them to consider alternative medicines and to avoid disease by introducing natural production conditions before antimicrobial treatment. This different mindset among organic farmers has also been identified in a French study (Hellec et al., 2021) and might be fostered through experience of low AMU or through the farmer's approach to organic farming and farming in general, and the farmer's reasons for farming organically. Literature has identified a distinction between farmers who perceive nature and diseases as things that should be controlled and defeated, and those who see nature as an ecosystem that they can learn from and be in symbiosis with (Verhoog et al., 2003; Kaltoft and Risgaard, 2006; Alrøe and Noe, 2008). This might explain some of the variation in farmers' approaches to treatment: perceiving a cow as part of an ecosystem could imply that diseased animals cause an imbalance for the whole system, and solutions might be sought from a holistic perspective. However, viewing a diseased cow as something that must be controlled might result in quick and effective intervention in the form of antimicrobial treatment.

The physical framework at the farm and suboptimal management have previously been reported as a barrier to prudent AMU (Buller et al., 2015; Ekakoro et al., 2018; Golding et al., 2019). The interviewed farmers in this study and their different approaches to handling the limitations caused by the local farm setting might also be explained by a difference in mindset among some organic and conventional farmers. Some interviewed farmers had seasonal calving, cows on pasture, and cow-calf contact within their farming systems, perhaps as a way of approaching challenges more holistically. In a study by Vaarst et al. (2006), organic farmers' approaches to and perceptions of the limitations of the physical framework seemed to vary according to farmers' progress toward zero AMU. Increasing success in eliminating antimicrobial treatment led to another way of thinking among farmers: that disease was no longer an expected disturbance that needed to be controlled; instead farmers allowed themselves to think about preventive measures such as outdoor access and using cows with chronically elevated SCC as nurse cows.

The role of the veterinarian varied widely across the interviewed farmers' herds, which is also supported by previous research (Raymond et al., 2006; Vaarst et al., 2006; Duval et al., 2016, 2017; Bonnaud and Fortané, 2020). Among interviewed farmers, the veterinarian's role spanned from performing legally determined tasks and skilled work to being an active collaborator and 
co-player, regardless of the type of production. It seems that improved understanding, communication, and goal-setting in the consultancy framework is necessary for veterinarians to become interesting partners for all types of farmers (Derks et al., 2012; Farrell et al., 2021; Skjølstrup et al., 2021).

As outlined in the Introduction, legislation has been a part of Danish farmers' antimicrobial landscape for decades. This might explain the general acceptance of the necessity of legislation among interviewed farmers - an attitude also identified among Swedish dairy farmers subject to similar restrictions (Fischer et al., 2019). In contrast, Swinkels et al. (2015) and Wemette et al. (2020) found that the recently imposed restrictions on AMU in the Netherlands and the USA, respectively, have led to negative feelings about legislation and society in general among some farmers. This attitude was also identified among some interviewed farmers in our study, primarily among conventional farmers. These farmers questioned the level of restrictions and where boundaries were drawn, and they appealed for more trust from society by allowing them to handle antimicrobials more liberally. The level of supervision was seen as a breach of trust and a lack of acknowledgment of their professionalism by society. It would appear that the liberalization of medicine use introduced in 2006 created a "do-it-yourself" culture among some Danish conventional farmers, who increasingly expect certain rights, and justify and allow themselves liberties, in relation to handling antimicrobials.

In contrast, many interviewed organic farmers appreciated the legislation as a way to ensure quality for consumers. Legislation thereby becomes an aid when marketing organic goods, potentially explaining their positive attitude toward it. A different mindset among some organic farmers adhering to organic principles might also explain this (Poizat et al., 2017). This mindset might be shaped by restrictions on AMU, which have increasingly become part of Danish organic values and principles, as outlined in the introduction (Jespersen et al., 2015).

Levels of legislation relating to AMU differ from country to country (Kahn, 2016). Previous research has illustrated how a changing discourse on AMR and AMU in agriculture, influenced by politicians, science, consumers, and the agricultural industry, has resulted in tighter or eased legislation over time. Based on these legislative changes, AMU has been problematized and legitimatized, respectively. As a result, differences in AMU and legislation levels among countries have increased (Begemann et al., 2018). The liberalization of medicine use for dairy farmers in Denmark in 2006 might have introduced a period of legitimatization, through which antimicrobials have almost become part of the infrastructure in some conventional farmers' landscape, alongside the intensification of dairy farming (Chandler, 2019; Denyer Willis and Chandler, 2019).

The frustration toward the media and consumers expressed by the interviewed farmers has also been identified previously (Swinkels et al., 2015; Ekakoro et al., 2018; Fischer et al., 2019; Golding et al., 2019; Wemette et al., 2020). However, the important role of consumers, the media, and politicians in shaping the future of farming and AMU has become evident from both our interviews and the literature (Haggerty et al., 2009; Begemann et al., 2018; Golding et al., 2019; Wemette et al., 2020). As outlined in the Introduction, megatrends among Danish consumers are well aligned with organic principles, explaining the increased demand for organic products. However, as evident from the interviewed farmers, as well as from previous studies (Ekakoro et al., 2018; Fischer et al., 2019; Wemette et al., 2020), consumers' distorted perception of dairy farming illustrates the need for better communication between agriculture and consumers for both conventional and organic farmers (Ritter et al., 2020). This could be achieved by holding more "Open Farm" events, as mentioned by the interviewed farmers, or through other consumer learning activities (Ventura et al., 2016).

Furthermore, continuous assessment among farmers, as identified in the interviews as well as in previous studies (Wemette et al., 2020), might lead to a positive competition toward prudent AMU. Organic farming might have had a head start on this journey due to its general principles and regulations on AMU, closer collaboration with consumers and targeted marketing, and a distinct differentiation from conventional farming (Stock, 2007), which seem to have created a feeling of coherence and collectiveness among organic farmers. This feeling has previously been shown to be important in reducing AMU (Adam et al., 2020). However, other farmers' opinions and practices are also of importance to farmers. Therefore, AMU reduction by pioneer farmers also tackling animal welfare issues, whether organic or conventional, might act as a driving force for other farmers.

These findings suggest that future research should focus on dialog about AMU and AMR among farmers from all production types and AMU levels, as a tool for increasing understanding and mutual motivation for changing AMU, as suggested by Hamilton (2018) and Vaarst et al. (2007). Meetings with farmers with different opinions about AMU might inspire changes in practices. Furthermore, future research should investigate whether constructive dialog between consumers, farmers, and representatives from the dairy industry can improve consumers' knowledge of dairy farming and thereby minimize misunderstandings, potentially 
giving farmers an increased incentive to work collaboratively with consumer preferences, preferably supporting reduction in AMU.

Several previous studies have identified a lack of knowledge with regard to AMR (Buller et al., 2015; Poizat et al., 2017; Ekakoro et al., 2018; Higham et al., 2018; Wemette et al., 2020). In this study, some of the interviewed farmers also explained that their knowledge and understanding of AMR and antimicrobials was limited. A lack of knowledge about AMR, or a lack of acknowledgment of AMU in agriculture as a risk factor for human AMR, as identified by Farrell et al. (2021), might also explain why AMR appeared to be a distant element of Danish dairy farmers' antimicrobial landscape. To truly appreciate the need to change something, it is vital to know, understand, and acknowledge the consequences of doing nothing (Kramer et al., 2017; Wemette et al., 2020). Golding et al. (2019) and Buller et al. (2015), however, did not identify a lack of knowledge about AMR among interviewed farmers. Instead, Golding and colleagues concluded that many barriers to antimicrobial stewardship exist (e.g., economic challenges), and AMR therefore remained a distant threat that was not acted upon. Similarly, poor housing conditions became a barrier for antimicrobial stewardship among some interviewed farmers in this study.

During the interview process, interviewees mentioned fewer and fewer new elements, which suggested that data saturation had been achieved. This was supported by the fact that a large variety of production types and farmers were included in the study. Having only one person analyzing the transcripts could be seen as a limitation of this study; however, this approach ensured consistency and alignment between the nonverbal results of the interviews, as experienced by the first author during the individual interviews, and the analysis. Qualitative research is not intended to be generalizable, but because the findings are understood and explained within a context, the knowledge gained from this is relevant in a global context and for discussions about the future path toward prudent AMU in general. A specific characterization of the Danish context is the low average AMU on a national level, with a large degree of legal control of AMU; antimicrobial landscape structures might appear different for farmers in other industries and countries. However, knowledge of how the type of production (organic vs. conventional) and changes in legislation might influence farmers' AMU can be beneficial in other national contexts as well. The Danish case can be seen as a critical case; controlling AMU through legislation has not resulted in a clear-cut reduction. Based on that knowledge, other countries can make informed reflections on whether AMU should be controlled primarily through legal restrictions or whether alternatives to this approach need to be considered as well.

\section{CONCLUSIONS}

This study showed that AMR appeared to be a distant element of Danish farmers' landscape, due to a lack of acknowledgment and understanding, as well as a tendency to blame others for the threat it poses. Daily practical challenges and urgent matters such as acutely diseased animals kept in poor housing conditions combined with the availability of medicines appeared to overrule the threat of AMR. We also identified pronounced differences in daily management and mindset among interviewed farmers, partly shaped by a changing antimicrobial landscape. Farming intensification and changes to legislation on AMU, such as the liberalization of medicines in Denmark in 2006, might have legitimized AMU and led to an independent and at times automatized use of antimicrobials among some interviewed conventional farmers. In contrast, some organic farmers focused on avoiding disease via robust animals and alternative housing conditions. Furthermore, they had a positive attitude toward legislation, potentially shaped by exposure to numerous restrictions on AMU over time, with consumer-related benefits. This difference in mindset and ongoing debate among farmers could act as a breeding ground for change, and future research should address the potential of such experience- and attitude-sharing to increase motivation to change AMU.

\section{ACKNOWLEDGMENTS}

This work was funded by the University of Copenhagen (Copenhagen, Denmark). The authors extend a special thank-you to all of the farmers who openly and willingly participated in the interviews and generously shared their personal thoughts and experiences of antimicrobial use. The authors declare that the research was conducted in the absence of any commercial or financial relationships that could be construed as a potential conflict of interest.

\section{REFERENCES}

Adam, C. J. M., N. Fortané, C. Ducrot, and M. C. Paul. 2020. Transition pathways toward the prudent use of antimicrobials: The case of free-range broiler farmers in France. Front. Vet. Sci. 7:548483. https://doi.org/10.3389/fvets.2020.548483.

Alrøe, H. F., and E. Noe. 2008. What makes organic agriculture move: Protest, meaning or market? A polyocular approach to the dynamics and governance of organic agriculture. Int. J. Agric. Resour. Gov. Ecol. 7:5-22. https://doi.org/10.1504/IJARGE.2008.016976.

Begemann, S., E. Perkins, I. Van Hoyweghen, R. Christley, and F. Watkins. 2018. How political cultures produce different antibiotic 
policies in agriculture: A historical comparative case study between the United Kingdom and Sweden. Sociol. Ruralis 58:765785. https://doi.org/10.1111/soru.12206.

Begemann, S., F. Watkins, I. Van Hoyweghen, R. Vivancos, R. Christley, and E. Perkins. 2020. The governance of UK dairy antibiotic use: Industry-led policy in action. Front. Vet. Sci. 7:557. https:// doi.org/10.3389/fvets.2020.00557.

Bennedsgaard, T. W., S. M. Thamsborg, M. Vaarst, and C. Enevoldsen. 2003. Eleven years of organic dairy production in Denmark: Herd health and production related to time of conversion and compared to conventional production. Livest. Prod. Sci. 80:121-131. https://doi.org/10.1016/S0301-6226(02)00312-3.

Bonnaud, L., and N. Fortané. 2020. Being a vet: The veterinary profession in social science research. Rev. Agric. Food Environ. Stud. 102:125-149. https://doi.org/10.1007/s41130-020-00103-1.

Booth, A., K. Hannes, A. Harden, J. Noyes, J. Harris, and A. Tong. 2014. COREQ (Consolidated Criteria for Reporting Qualitative Studies). Pages 214-226 in Guidelines for Reporting Health Research: A User's Manual. D. Moher, D. G. Altman, K. F. Schulz, I. Simera, and E. Wager, ed. John Wiley and Sons Ltd.

Bro, D. S. 2021. Som Lovet: Mælkeprisen Stiger i Marts [in Danish]. Accessed Feb. 9, 2021. https://landbrugsavisen.dk/som-lovet -mælkeprisen-stiger-i-marts.

Buller, H., S. Hinchliffe, J. Hockenhull, D. Barrett, K. Reyher, A. Butterworth, and C. Heath. 2015. Systematic review and social research to further understanding of current practice in the context of using antimicrobials in livestock farming and to inform appropriate interventions to reduce antimicrobial resistance within the livestock sector. Department for Environment, Food and Rural Affairs, London, UK. Accessed May 2, 2019. http://randd.defra .gov.uk/Default.aspx?Menu=Menu\&Module $=$ More\&Location $=$ None\&Completed $=0 \&$ ProjectID $=19623$.

Chandler, C. I. R. 2019. Current accounts of antimicrobial resistance: Stabilisation, individualisation and antibiotics as infrastructure. Palgrave Commun. 5:53. https://doi.org/10.1057/s41599-019-0263 -4 .

Clay, N., T. Garnett, and J. Lorimer. 2020. Dairy intensification: Drivers, impacts and alternatives. Ambio 49:35-48. https://doi.org/10 .1007/s13280-019-01177-y.

Corbin, J., and A. Strauss. 2015. Basics of Qualitative Research: Techniques and Procedures for Developing Grounded Theory. 4th ed. Sage Publications.

Danish Agricultural Agency and Ministry of Food, Agriculture and Fisheries of Denmark. 2018. Vejledning om økologisk jordbrugsproduktion [in Danish]. March 2018. Augustenborg, Denmark.

Denyer Willis, L., and C. Chandler. 2019. Quick fix for care, productivity, hygiene and inequality: Reframing the entrenched problem of antibiotic overuse. BMJ Glob. Health 4:e001590. https://doi .org/10.1136/bmjgh-2019-001590.

Derks, M., L. M. A. van de Ven, T. van Werven, W. D. J. Kremer, and H. Hogeveen. 2012. The perception of veterinary herd health management by Dutch dairy farmers and its current status in the Netherlands: A survey. Prev. Vet. Med. 104:207-215. https://doi .org/10.1016/j.prevetmed.2011.12.019.

Doidge, C., E. Ferguson, F. Lovatt, and J. Kaler. 2021. Understanding farmers' naturalistic decision making around prophylactic antibiotic use in lambs using a grounded theory and natural language processing approach. Prev. Vet. Med. 186:105226. https://doi.org/ 10.1016/j.prevetmed.2020.105226.

Duval, J. E., N. Bareille, C. Fourichon, A. Madouasse, and M. Vaarst. 2016. Perceptions of French private veterinary practitioners on their role in organic dairy farms and opportunities to improve their advisory services for organic dairy farmers. Prev. Vet. Med. 133:10-21. https://doi.org/10.1016/j.prevetmed.2016.09.008.

Duval, J. E., N. Bareille, C. Fourichon, A. Madouasse, and M. Vaarst. 2017. How can veterinarians be interesting partners for organic dairy farmers? French farmers' point of views. Prev. Vet. Med. 146:16-26. https://doi.org/10.1016/j.prevetmed.2017.07.013.

Ekakoro, J. E., M. Caldwell, E. B. Strand, and C. C. Okafor. 2018. Drivers of antimicrobial use practices among Tennessee dairy cattle producers. Vet. Med. Int. 2018:1836836. https://doi.org/10 $.1155 / 2018 / 1836836$.

EMA (European Medicines Agency). 2020. Sales of veterinary antimicrobial agents in 31 European countries in 2018: Trends from 2010 to 2018. Tenth ESVAC report. EMA.

Emanuelson, U., K. Sjöström, and N. Fall. 2018. Biosecurity and animal disease management in organic and conventional Swedish dairy herds: A questionnaire study. Acta Vet. Scand. 60:23. https: //doi.org/10.1186/s13028-018-0376-6.

Farrell, S., C. McKernan, T. Benson, C. Elliott, and M. Dean. 2021. Understanding farmers' and veterinarians' behavior in relation to antimicrobial use and resistance in dairy cattle: A systematic review. J. Dairy Sci. 104:4584-4603. https://doi.org/10.3168/jds .2020-19614.

Fischer, K., K. Sjöström, A. Stiernström, and U. Emanuelson. 2019. Dairy farmers' perspectives on antibiotic use: A qualitative study. J. Dairy Sci. 102:2724-2737. https://doi.org/10.3168/jds.2018 $-15015$.

Fusch, P. I., and L. R. Ness. 2015. Are we there yet? Data saturation in qualitative research. Qual. Rep. 20:1408-1416.

Golding, S. E., J. Ogden, and H. M. Higgins. 2019. Shared goals, different barriers: A qualitative study of UK veterinarians' and farmers' beliefs about antimicrobial resistance and stewardship. Front. Vet. Sci. 6:132. https://doi.org/10.3389/fvets.2019.00132.

Grunert, K. G., T. Bech-Larsen, and L. Bredahl. 2000. Three issues in consumer quality perception and acceptance of dairy products. Int. Dairy J. 10:575-584. https://doi.org/10.1016/S0958 -6946(00)00085-6.

Habing, G., C. Djordjevic, G. M. Schuenemann, and J. Lakritz. 2016. Understanding antimicrobial stewardship: Disease severity treatment thresholds and antimicrobial alternatives among organic and conventional calf producers. Prev. Vet. Med. 130:77-85. https:// doi.org/10.1016/j.prevetmed.2016.06.004.

Haggerty, J., H. Campbell, and C. Morris. 2009. Keeping the stress off the sheep? Agricultural intensification, neoliberalism, and "good" farming in New Zealand. Geoforum 40:767-777. https://doi.org/10 .1016/j.geoforum.2008.12.003.

Halberg, N., H. F. Alrøe, M. Meldgaard, and J. Michelsen. 2008. Development, Growth and Integrity in the Danish Organic Sector: A Knowledge Synthesis on the Opportunities and Barriers for a Continued Development and Market-Based Growth in Production, Processing, and Sale of Organic Products. ICROFS.

Hamilton, L. 2018. Bridging the divide between theory and practice: Taking a co-productive approach to vet-farmer relationships. Food Ethics 1:221-233. https://doi.org/10.1007/s41055-017-0011-7.

Hellec, F., C. Manoli, and M. de Joybert. 2021. Alternative medicines on the farm: A study of dairy farmers' experiences in France. Front. Vet. Sci. 8:563957. https://doi.org/10.3389/fvets.2021.563957.

Higham, L. E., A. Deakin, E. Tivey, V. Porteus, S. Ridgway, and A. C. Rayner. 2018. A survey of dairy cow farmers in the United Kingdom: Knowledge, attitudes and practices surrounding antimicrobial use and resistance. Vet. Rec. 183:746. https://doi.org/ 10.1136/vr.104986.

Jespersen, L. M., J. Krabsen, H. Kristensen, and N. Halberg. 2015. The Contribution of Organic Farming to Public Goods in Denmark: Knowledge Synthesis 2015. ICROFS.

Kahn, L. H. 2016. One Health and the Politics of Antimicrobial Resistance. Johns Hopkins University Press.

Kaltoft, P., and M. L. Risgaard. 2006. Has organic farming modernized itself out of business? Reverting to conventional methods in Denmark. Pages 126-141 in Sociological Perspectives of Organic Agriculture: From Pioneer to Policy. G. Holt and M. Reed, ed. CAB International.

Korsgaard, H., J. Ellis-Iversen, U. W. Sönksen, and S. Skovgaard. 2020. DANMAP 2019 - Use of antimicrobial agents and occurence of antimicrobial resistance in bacteria from food animals, food and humans in Denmark. Statens Serum Institut, National Food Institute, Technical University of Denmark.

KPMG. 2018. Global Organic Milk Production Market Report. KPMG. 
Kramer, T., L. E. Jansen, L. J. A. Lipman, L. A. M. Smit, D. J. J. Heederik, and A. Dorado-García. 2017. Farmers' knowledge and expectations of antimicrobial use and resistance are strongly related to usage in Dutch livestock sectors. Prev. Vet. Med. 147:142148. https://doi.org/10.1016/j.prevetmed.2017.08.023.

Krogh, M. A., C. L. Nielsen, and J. T. Sørensen. 2020. Antimicrobial use in organic and conventional dairy herds. Animal 14:2187-2193. https://doi.org/10.1017/S1751731120000920.

Laxminarayan, R., A. Duse, C. Wattal, A. K. M. Zaidi, H. F. L. Wertheim, N. Sumpradit, E. Vlieghe, G. L. Hara, I. M. Gould, H. Goossens, C. Greko, A. D. So, M. Bigdeli, G. Tomson, W. Woodhouse, E. Ombaka, A. Q. Peralta, F. N. Qamar, F. Mir, S. Kariuki, Z. A. Bhutta, A. Coates, R. Bergstrom, G. D. Wright, E. D. Brown, and O. Cars. 2013. Antibiotic resistance - The need for global solutions. Lancet Infect. Dis. 13:1057-1098. https://doi.org/10.1016/ S1473-3099(13)70318-9.

McIntosh, W., and W. Dean. 2015. Factors associated with the inappropriate use of antimicrobials. Zoonoses Public Health 62:22-28. https://doi.org/10.1111/zph.12169.

Ministry of Environment and Food of Denmark. 2018. Bekendtgørelse om sundhedsrådgivningsaftaler for kvægbesætninger [in Danish]. BEK nr. 1649 af 18/12/2018. Ministry of Environment and Food of Denmark.

OECD/FAO (Food and Agriculture organization of the United Nations). 2018. Dairy and dairy products. Pages 164-174 in Agricultural Outlook 2018-2027. OECD Publishing/Food and Agriculture Organization of the United Nations.

Olmos Antillón, G., K. Sjöström, N. Fall, S. Sternberg Lewerin, and U. Emanuelson. 2020. Antibiotic use in organic and non-organic Swedish dairy farms: A comparison of three recording methods. Front. Vet. Sci. 7:568881. https://doi.org/10.3389/fvets.2020 .568881 .

Organic Denmark, Danish Agriculture and Food Council, and The Danish Dairy Board. 2020. Anbefalinger for at højne dyrevelfærd, miljø og etik ved produktion af $\varnothing$ kologisk mælk og kød fra bedrifter med kreaturer [in Danish]. Organic Denmark, Danish Agriculture and Food Council, and The Danish Dairy Board.

Ormond, J. 2016. The transition to low carbon milk: Dairy consumption and the changing politics of human-animal relations. Chapter 9 in Why We Eat, How We Eat, 1st ed. E.-J. Abbots and A. Lavis, ed. Routledge.

Poizat, A., F. Bonnet-Beaugrand, A. Rault, C. Fourichon, and N. Bareille. 2017. Antibiotic use by farmers to control mastitis as influenced by health advice and dairy farming systems. Prev. Vet. Med. 146:61-72. https://doi.org/10.1016/j.prevetmed.2017.07.016.

Raymond, M. J., R. D. Wohrle, and D. R. Call. 2006. Assessment and promotion of judicious antibiotic use on dairy farms in Washington State. J. Dairy Sci. 89:3228-3240. https://doi.org/10.3168/jds .S0022-0302(06)72598-X.

Ritter, C., K. E. Mills, D. M. Weary, and M. A. G. von Keyserlingk. 2020. Perspectives of western Canadian dairy farmers on the future of farming. J. Dairy Sci. 103:10273-10282. https://doi.org/10 $.3168 /$ jds.2020-18430

Rynkiewich, K. 2020. Finding "What's wrong with us": Antibiotic prescribing practice among physicians in the United States. Front. Sociol. 5:5. https://doi.org/10.3389/fsoc.2020.00005.

Skjølstrup, N. K., L. R. Nielsen, C. S. Jensen, and D. B. Lastein. 2021. Veterinary herd health consultancy and antimicrobial use in dairy herds. Front. Vet. Sci. 7:547975. https://doi.org/10.3389/ fvets.2020.547975.

Statistics Denmark. 2019. Kvægbestanden 31. December 2018 [in Danish]. Accessed Feb. 9, 2021. https://www.dst.dk/Site/Dst/ Udgivelser/nyt/GetPdf.aspx?cid=30364.

Statistics Denmark. 2020. Detailomsætningen af $\varnothing$ kologiske fødevarer 2019 [in Danish]. Accessed Feb. 9, 2021. https://www.dst.dk/Site/ Dst/Udgivelser/nyt/GetPdf/aspx?cid=30678.
Stock, P. V. 2007. 'Good farmers' as reflexive producers: An examination of family organic farmers in the US Midwest. Sociol. Ruralis 47:83-102. https://doi.org/10.1111/j.1467-9523.2007.00429.x.

Swinkels, J. M., A. Hilkens, V. Zoche-Golob, V. Krömker, M. Buddiger, J. Jansen, and T. J. G. M. Lam. 2015. Social influences on the duration of antibiotic treatment of clinical mastitis in dairy cows. J. Dairy Sci. 98:2369-2380. https://doi.org/10.3168/jds.2014 -8488 .

Tang, K. L., N. P. Caffrey, D. B. Nóbrega, S. C. Cork, P. E. Ronksley, H. W. Barkema, A. J. Polachek, H. Ganshorn, N. Sharma, J. D Kellner, and W. A. Ghali. 2017. Restricting the use of antibiotics in food-producing animals and its associations with antibiotic resistance in food-producing animals and human beings: A systematic review and meta-analysis. Lancet Planet. Health 1:e316-e327. https://doi.org/10.1016/S2542-5196(17)30141-9.

Tsing, A. 2017. The buck, the bull, and the dream of the stag: Some unexpected weeds of the Anthropocene. Suom. Antropol. 42:3-21.

Vaarst, M., T. W. Bennedsgaard, I. Klaas, T. B. Nissen, S. M. Thamsborg, and S. Østergaard. 2006. Development and daily management of an explicit strategy of nonuse of antimicrobial drugs in twelve Danish organic dairy herds. J. Dairy Sci. 89:1842-1853. https://doi.org/10.3168/jds.S0022-0302(06)72253-6.

Vaarst, M., T. B. Nissen, S. Østergaard, I. C. Klaas, T. W. Bennedsgaard, and J. Christensen. 2007. Danish stable schools for experiential common learning in groups of organic dairy farmers. J. Dairy Sci. 90:2543-2554. https://doi.org/10.3168/jds.2006-607.

Vaarst, M., B. Paarup-Laursen, H. Houe, C. Fossing, and H. J. Andersen. 2002. Farmers' choice of medical treatment of mastitis in Danish dairy herds based on qualitative research interviews. J. Dairy Sci. 85:992-1001. https://doi.org/10.3168/jds.S0022 $-0302(02) 74159-3$

Vaarst, M., S. M. Thamsborg, T. W. Bennedsgaard, H. Houe, C. Enevoldsen, F. M. Aarestrup, and A. de Snoo. 2003. Organic dairy farmers' decision making in the first 2 years after conversion in relation to mastitis treatments. Livest. Prod. Sci. 80:109-120. https: //doi.org/10.1016/S0301-6226(02)00310-X.

Ventura, B. A., M. A. G. Von Keyserlingk, H. Wittman, and D. M. Weary. 2016. What difference does a visit make? Changes in animal welfare perceptions after interested citizens tour a dairy farm. PLoS One 11:e0154733. https://doi.org/10.1371/journal.pone .0154733 .

Verhoog, H., M. Matze, E. Lammerts van Bueren, and T. Baars. 2003. The role of the concept of the natural (naturalness) in organic farming. J. Agric. Environ. Ethics 16:29-49. https://doi.org/10 .1023/A:1021714632012.

Wemette, M., A. G. Safi, W. Beauvais, K. Ceres, M. Shapiro, P. Moroni, F. L. Welcome, and R. Ivanek. 2020. New York State dairy farmers' perceptions of antibiotic use and resistance: A qualitative interview study. PLoS One 15:e0232937. https://doi.org/10.1371/ journal.pone.0232937.

WHO (World Health Organization). 2015. Global Action Plan on Antimicrobial Resistance. WHO.

Zwald, A. G., P. L. Ruegg, J. B. Kaneene, L. D. Warnick, S. J. Wells, C. Fossler, and L. W. Halbert. 2004. Management practices and reported antimicrobial usage on conventional and organic dairy farms. J. Dairy Sci. 87:191-201. https://doi.org/10.3168/jds.S0022 -0302(04)73158-6.

\section{ORCIDS}

Nanna K. Skjølstrup ( https://orcid.org/0000-0001-9863-3348 Dorte B. Lastein ๑ https://orcid.org/0000-0003-3628-5418 Carsten S. Jensen ๑ https://orcid.org/0000-0002-5760-9648 Mette Vaarst @ https://orcid.org/0000-0003-2830-2847 


\section{APPENDIX}

Table A1. Coding tree visualizing the inductive process going from interview statements and meaning condensates to codes and themes

\begin{tabular}{|c|c|c|c|}
\hline Example: Meaning condensate and statement & Codes & Themes & \\
\hline $\begin{array}{l}\text { Economy: } \\
\text { "It's expensive to call the veterinarian, especially when } \\
\text { we can make some of the diagnosis on our own. Then you } \\
\text { start off doing that." }\end{array}$ & $\begin{array}{l}\text { Economy } \\
\text { Available products } \\
\text { Robustness and naturalness } \\
\text { Type of antimicrobial } \\
\text { Causing bacteria } \\
\text { Timing and length of treatment }\end{array}$ & $\begin{array}{l}\text { Treatment and } \\
\text { decisions }\end{array}$ & $\begin{array}{l}\text { Available toolbox for } \\
\text { treatments }\end{array}$ \\
\hline $\begin{array}{l}\text { Influences between farmer and veterinarian: } \\
\text { "My veterinarian once taught me that I should finish the } \\
\text { course of treatment, because otherwise the animals could } \\
\text { get resistant." }\end{array}$ & $\begin{array}{l}\text { Avoid using antimicrobials } \\
\text { Responsibility of the veterinarian } \\
\text { Use of "penicillin" } \\
\text { Different perceptions (criteria, } \\
\text { length, type of antimicrobials) } \\
\text { Learning by doing } \\
\text { Influences between farmer and } \\
\text { veterinarian }\end{array}$ & $\begin{array}{l}\text { "Correct" use of } \\
\text { antimicrobials }\end{array}$ & \\
\hline $\begin{array}{l}\text { Type of production-robustness: } \\
\text { "It's all about creating robust cows that can survive on } \\
\text { grass." }\end{array}$ & $\begin{array}{l}\text { Employees } \\
\text { Barn conditions } \\
\text { Type of production-robustness }\end{array}$ & $\begin{array}{l}\text { Framework of the } \\
\text { farm }\end{array}$ & Local farm setting \\
\hline $\begin{array}{l}\text { Accepted, a necessity: } \\
\text { "Yes, we need to register our medicine use, and they keep } \\
\text { an eye on us. But I think it is okay. It ensures that we } \\
\text { don't treat like crazy." }\end{array}$ & $\begin{array}{l}\text { Accepted, a necessity, a way to } \\
\text { differentiate } \\
\text { For the sake of the animal } \\
\text { Something that can be changed } \\
\text { Meaningless, lack of trust, } \\
\text { frustrating }\end{array}$ & Legislation & Legislative structures \\
\hline $\begin{array}{l}\text { Conventional farmers use more antimicrobials: } \\
\text { "I don't know how things go about, but I imagine that it } \\
\text { is much more focused on treatment." }\end{array}$ & $\begin{array}{l}\text { Conventional farmers use more } \\
\text { antimicrobials } \\
\text { Lack of painkillers in organic } \\
\text { farming — animal welfare issues }\end{array}$ & Others & $\begin{array}{l}\text { Other influential } \\
\text { actors }\end{array}$ \\
\hline
\end{tabular}

